\title{
Effects of defaunation on fermentation characteristics and biotin balance in an artificial rumen-simulation system (RUSITEC) receiving diets with different amounts and types of cereal
}

\author{
H. Abel $^{1 *}$, B. Schröder ${ }^{1}$, P. Lebzien ${ }^{2}$ and G. Flachowsky ${ }^{2}$ \\ ${ }^{1}$ Institute of Animal Physiology and Nutrition, Georg-August University of Goettingen, Germany \\ ${ }^{2}$ Institute of Animal Nutrition, Federal Agricultural Research Centre (FAL), Braunschweig, Germany \\ (Received 15 March 2005 - Revised 4 August 2005 - Accepted 22 August 2005)
}

\begin{abstract}
Biotin is required by rumen microbes for efficient fermentation. To evaluate the role of protozoa in ruminal biotin metabolism, five diets composed of grass hay or of grass hay/cereal grain mixtures were supplied to faunated or defaunated RUSITEC fermenters. In the mixed diets, hay was replaced to 33:67 or 67:33 w/w on an air-dried basis by either wheat or maize grain in order to simulate different cellulolytic and amylolytic fermentation conditions. Defaunation increased SCFA production, whereas $\mathrm{NH}_{4}$ concentration and the release of $\mathrm{CH}_{4}$ were reduced. Biotin input declined when cereal grain was used to replace the hay. With the exception of the high-wheat treatment, defaunated fermenters yielded higher biotin outputs than faunated fermenters. The biotin balance, calculated as the difference between the total biotin output (biotin in the solid residue contained in the nylon bags after fermentation plus the biotin in the effluent) and the biotin input with the feed, was negative for all the dietary treatments apart from fermenters supplied with the high-maize diet. It was less negative or, in the case of the high-maize diets, more positive for defaunated compared with faunated fermenters. It was concluded that, under normal faunated conditions, protozoa directly utilise or indirectly affect the bacterial synthesis and/or utilisation of biotin. With diets of a high fermentation potential, as realised with the high-wheat diet, protozoa prevent the development of a bacterial population that would utilise high or synthesise low amounts of biotin.
\end{abstract}

Biotin: Protozoa: RUSITEC

The vitamin biotin constitutes an essential cofactor in transcarboxylation reactions, which play an important role in the overall fermentation process in the rumen. Biotin-dependent transcarboxylations are particularly involved in the succinate, or randomisation, pathway for propionate production associated with the activity of many ruminal cellulolytic species. When starch or soluble carbohydrates serve as the dominant substrates, there is a shift to the direct formation of propionate via the biotin-independent acrylate pathway (Milligan et al. 1967; Scheifinger \& Wolin, 1973).

It is generally assumed that B vitamins are synthesised by ruminal microbes (Wolin \& Miller, 1988). With regard to biotin, a low ruminal degradation of the vitamin supplied with the feed has been observed in heifers (Frigg et al. 1993), and even a lack of ruminal destruction of the vitamin has been suggested from studies in duodenally cannulated steer calves (Zinn et al. 1987). However, microbial biotin utilisers and producers appear to be influenced by forage type and $\mathrm{pH}$, suggesting a reduced utilisation at a low $\mathrm{pH}$ as the result of a lower growth of cellulolytic microbes (Rosendo et al. 2003a,b). Decreasing biotin concentrations of ruminal fluid with the increasing age of suckling lambs provided little evidence for a net biotin synthesis of ruminal micro-organisms (Poe et al. 1972). Similarly, the amounts of dietary biotin corresponded almost quantitatively to biotin flows in the duodenum of dairy cows, thereby questioning ruminal synthesis, even though biotin utilisation and synthesis may have occurred at the same rate (Santschi et al. 2005).

There is evidence from in vivo studies that not only the proportion of cereal grain fed in the ration, but also the type of grain used influences biotin metabolism in the rumen (Miller et al. 1986). In a preliminary study from our laboratory applying the rumen-simulation technique (RUSITEC), the stepwise replacement of grass hay by barley led to a significant reduction in the net output of biotin by microbial metabolism (Abel et al. 2001). We speculated that the simultaneously elevated number of protozoa might have been involved. Therefore, the present experiment was designed to study the effects of defaunation on fermentation characteristics and biotin balance in RUSITEC systems receiving hay alone or diets with increasing proportions of cereal grains in place of hay. A late-cut fibrous hay was chosen in order to support an effective cellulolytic microbial population, whereas wheat served as a readily fermentable, and maize as a less degradable, source of carbohydrate substrate for rumen microbes. 


\section{Methods}

The RUSITEC followed the same procedure described by Czerkawski \& Breckenridge (1977) simultaneously operating ten fermenters of $1000 \mathrm{ml}$ capacity each. The inoculum was obtained from three rumen-fistulated Jersey steers. Each animal (approximately $600 \mathrm{~kg}$ body weight) consumed 5$7 \mathrm{~kg}$ grass hay $/ \mathrm{d}$ in addition to two $0.25 \mathrm{~kg}$ portions of a commercial mineral- and vitamin-supplemented concentrate for cattle (type MLF 26; HEMO Mohr GmbH, Scheden, Germany; declared to contain, per $\mathrm{kg}$ air-dried substance, $200 \mathrm{~g}$ crude protein, $7 \mathrm{~g} \mathrm{Ca}, 4 \mathrm{~g} \mathrm{P}, 2 \mathrm{~g} \mathrm{Na}, 3000 \mu \mathrm{g}$ vitamin A, $31 \mu \mathrm{g}$ cholecalciferol).

Each fermenter was filled with $750 \mathrm{ml}$ rumen fluid and $250 \mathrm{ml}$ buffer (McDougall, 1948). The buffer flow rate was $460-520 \mathrm{ml} / \mathrm{d}$, equivalent to a dilution rate of $0.46-0.52 / \mathrm{d}$. Five feed rations were supplied at random to the fermenters in five identical runs. The daily rations consisted of either $12 \mathrm{~g}$ grass hay $(12 \mathrm{H})$ or hay/cereal mixtures including $8 \mathrm{~g}$ hay and $4 \mathrm{~g}$ wheat $(8 \mathrm{H} 4 \mathrm{~W})$ or maize $(8 \mathrm{H} 4 \mathrm{M})$, or $4 \mathrm{~g}$ hay and $8 \mathrm{~g}$ wheat $(4 \mathrm{H} 8 \mathrm{~W})$ or maize $(4 \mathrm{H} 8 \mathrm{M})$, as air-dry substances. Each feed ration was supplemented with $0.15 \mathrm{~g}$ of a vitaminised mineral mixture (type Movikalin 22/3; HEMO Mohr $\mathrm{GmbH}$; declared to contain per kg air-dry substance 220 g Ca, 110 g Na, 30 g Mg, 30 g P, 4000 mg Mn, 8000 mg $\mathrm{Zn}, 80 \mathrm{mg}$ I, $60 \mathrm{mg}$ Se, $80 \mathrm{mg}$ Co, $150000 \mu \mathrm{g}$ vitamin A, $1562 \mu \mathrm{g}$ cholecalciferol). The hay was manually chopped to an average particle size of $4-5 \mathrm{~mm}$, and the cereal grains were milled (Retsch type ZM1; Retsch GmbH, Haan, Germany) using a $2 \mathrm{~mm}$ screen. The DM and chemical composition of the experimental diets were analysed according to standard methods (Naumann \& Bassler, 1997) and are given in Table 1. A late-cut hay rich in cell wall constituents was chosen in order to establish an effective cellulolytic microbial population.

The daily feed rations were supplied in nylon bags with a pore size of $100 \mu \mathrm{m}$. For defaunation, $2.68 \mathrm{ml}$ Synperonic (sodium lauryldiethoxysulfate; Deutsche ICI, Frankfurt/Main, Germany) were added to the fermenter on the first day of each experimental run. Each run lasted $15 \mathrm{~d}$, which included $10 \mathrm{~d}$ adaptation (days 1-10) and $5 \mathrm{~d}$ sample collection (days $11-15)$. The nylon bags containing the solid residues after fermentation were transferred each day to polyethylene bags and washed with $60 \mathrm{ml}$ buffer. After manual squeezing of the nylon bags within the polyethylene bag, the buffer was put back into the fermenter.
During the collection periods, $10 \mathrm{ml}$ fluid samples were drawn daily directly from each fermenter for the determination of $\mathrm{pH}$ and $\mathrm{NH}_{3} \mathrm{~N}$ concentration before replacing the feed substrate. $\mathrm{NH}_{3} \mathrm{~N}$ was determined by means of an electrode $(\mathrm{NH}$ 1100; Schott Duran GmbH, Mainz, Germany; calibrated daily with serial dilutions of an $\mathrm{NH}_{4} \mathrm{Cl}$ stock solution) connected to a pH meter (CG 817; Schott Duran GmbH). Fermentation gases were collected daily in gas-proof bags and quantified by the corresponding replacement of water. The $\mathrm{CH}_{4}$ content of fermentation gases was analysed in replicate samples by GC on a packed Porapak Q-column 80/100 (Alltech $\mathrm{GmbH}$, Unterhaching, Germany) at $80^{\circ} \mathrm{C}$ injection port and detector temperature, and $40^{\circ} \mathrm{C}$ column temperature (isothermal). The GC was equipped with a thermal conductivity detector (Shimadzu C-R 1B; Shimadzu Deutschland $\mathrm{GmbH}$, Duisburg, Germany) and Ar served as the carrier gas.

For protozoa counting, $2 \mathrm{ml}$ samples of fermenter fluid were taken daily immediately before substrate exchange. The fluid samples were carefully mixed with $2 \mathrm{ml}$ of a solution of $0.6 \mathrm{~g}$ methyl green (E. Merck, Darmstadt, Germany), $6 \mathrm{~g}$ $\mathrm{NaCl}$ and $100 \mathrm{ml}$ formaldehyde $(35 \%)$ filled upto $1000 \mathrm{ml}$ aqua dest. Portions of the samples were then pipetted into a $0.98 \mathrm{~mm}$ depth McMaster counting chamber (Kleinfeld Labortechnik $\mathrm{GmbH}$, Gehrden, Germany). Microscopic counting without quantifying different types of protozoon was performed using a 16/0.35 objective (Carl Zeiss AG, Goettingen, Germany).

Aliquot portions (10\%) of the daily effluent of each fermenter sampled during the collection periods were stored frozen and, after thawing, served for the preparation of the pooled samples for analysing SCFA by GC. Replicate samples of the pooled effluents of each fermenter were submitted to a combined internal/external standard procedure for SCFA using a packed column (10\% Carbowax 20 MTPA with $1 \%$ $\mathrm{H}_{3} \mathrm{PO}_{4}$ on Chromosorb WAW, 80/100; Alltech $\mathrm{GmbH}$ ). The temperature of the injection port and detector was adjusted to $200^{\circ} \mathrm{C}$, and that of the column to $120^{\circ} \mathrm{C}$ (isothermal). The GC was equipped with a flame ionisation detector (Shimadzu GC 14B; Shimadzu Deutschland $\mathrm{GmbH}$ ), and $\mathrm{H}$ served as the carrier gas.

For biotin analysis, daily aliquot fluid samples of the individual fermenter effluents $(20 \%)$ and the complete daily samples of the solid residues contained in the nylon bags after incubation were stored frozen at $-20^{\circ} \mathrm{C}$ until further analysis. After thawing, the fluid samples were pooled per fermenter and collection period, and were analysed as fresh

Table 1. DM and nutrient content of the feed rations $(\mathrm{g} / \mathrm{kg})$

\begin{tabular}{|c|c|c|c|c|c|}
\hline \multirow[b]{2}{*}{ Ingredient } & \multicolumn{5}{|c|}{ Feed ration } \\
\hline & $\begin{array}{c}12 \mathrm{~g} \text { hay } \\
(12 \mathrm{H})\end{array}$ & $\begin{array}{c}8 \mathrm{~g} \text { hay }+4 \mathrm{~g} \text { wheat } \\
(8 \mathrm{H} 4 \mathrm{~W})\end{array}$ & $\begin{array}{c}8 \mathrm{~g} \text { hay }+4 \mathrm{~g} \text { maize } \\
(8 \mathrm{H} 4 \mathrm{M})\end{array}$ & $\begin{array}{c}4 \mathrm{~g} \text { hay }+8 \mathrm{~g} \text { wheat } \\
(4 \mathrm{H} 8 \mathrm{~W})\end{array}$ & $\begin{array}{c}4 \mathrm{~g} \text { hay }+8 \mathrm{~g} \text { maize } \\
(4 \mathrm{H} 8 \mathrm{M})\end{array}$ \\
\hline DM & 915 & 921 & 920 & 915 & 912 \\
\hline Crude ash & 62 & 56 & 55 & 40 & 39 \\
\hline Crude protein $(\mathrm{N} \times 6.25)$ & 108 & 113 & 101 & 117 & 95 \\
\hline Crude fat & 16 & 17 & 21 & 18 & 26 \\
\hline Crude fibre & 362 & 251 & 250 & 140 & 137 \\
\hline $\mathrm{N}$-free extractants & 367 & 484 & 493 & 600 & 615 \\
\hline Neutral detergent fibre & 702 & 515 & 501 & 328 & 300 \\
\hline Acid detergent fibre & 369 & 253 & 254 & 138 & 138 \\
\hline
\end{tabular}


material. The solid residues underwent freeze-drying before they were pooled and analysed per fermenter and collection period. Duplicate samples of the liquid phases and solid residues as well as the feed rations were analysed for biotin, applying a microbiological method (Frigg \& Brubacher, 1976). In brief, using this method, biotin was liberated from the samples by acid hydrolysis followed by enzymatic treatment with papain. After incubation with Lactobacillus plantarum (ATCC 8014), the increase in the turbidity of the cell suspensions was measured at $600 \mathrm{~nm}$.

For statistical evaluation, daily analysed data (protozoa counts, $\mathrm{pH}, \mathrm{NH}_{4}, \mathrm{CH}_{4}$ ) were averaged, resulting in one mean per criterion and experimental run, thus corresponding to SCFA and biotin data, which were obtained from one analysis of one pooled sample per fermenter and experimental run. Accordingly, a consistent number of five values per criteria and dietary treatment, faunated and defaunated respectively, were submitted to statistical evaluation (ANOVA) using the SAS program (Version 6.12, SAS Institute Inc., Cary, NC, USA) according to the split-plot model with defaunation as the main plot:

$$
Y_{\mathrm{ijk}}=\mu+a_{\mathrm{i}}+b_{\mathrm{j}}+c_{\mathrm{k}}+d: b_{\mathrm{lj}}+(b c)_{\mathrm{jk}}+e_{\mathrm{ijk} \mathrm{l}},
$$

where $\mu$ is the overall mean, $a_{\mathrm{i}}$ the effect of the ith experimental run $(i=1, \ldots 5), b_{\mathrm{j}}$ the effect of the $\mathrm{jth}$ faunation status $(j=1,2), c_{\mathrm{k}}$ the effect of the kth ration $(k=1, \ldots .5), d: b_{\mathrm{lj}}$ the fermenter within faunation status $(l=1, \ldots 5),(b c)_{\mathrm{jk}}$ the interaction effect between faunation status and ration, and $e_{\mathrm{ijkl}}$ the residual term. The effect of faunation status was tested against fermenter within faunation status (error A). The effects of ration and of interaction between faunation status and ration were tested against the residual term (error B). Linear contrasts were calculated to evaluate the effects of type and level of cereal grain respectively.

\section{Results}

The effects of defaunation and the five different feed rations on protozoa concentrations, $\mathrm{pH}, \mathrm{NH}_{4}$ concentrations, $\mathrm{CH}_{4}$ and SCFA production, as well as the distribution of individual SCFA in the fermenters, are shown in Table 2. The protozoa were almost eliminated by defaunation. In the faunated fermenters, the partial replacement of hay by cereal grain led to elevated protozoal counts, wheat being more effective than maize. However, the exchange of one third of the hay with cereal grain was associated with higher protozoal concentrations than were seen when two-thirds were replaced.

Defaunation decreased the $\mathrm{pH}$ only in the fermenters receiving the high-wheat ration, thus leading to a weak interaction between faunation status and ration. The $\mathrm{pH}$ was also reduced with increasing level of cereal grain, wheat being more effective than maize. The $\mathrm{NH}_{4}$ concentration in the fermenter fluid was reduced by defaunation, as well as by maize compared with wheat. Defaunation clearly decreased $\mathrm{CH}_{4}$ production. Faunated fermenters supplied with the high-wheat diet indeed produced the highest amounts of $\mathrm{CH}_{4}$; however, on average of all the rations supplied, the mixed hay/cereal diets led to a lower $\mathrm{CH}_{4}$ release than the pure hay rations, and the maize-supplied fermenters released less $\mathrm{CH}_{4}$ than those receiving wheat.

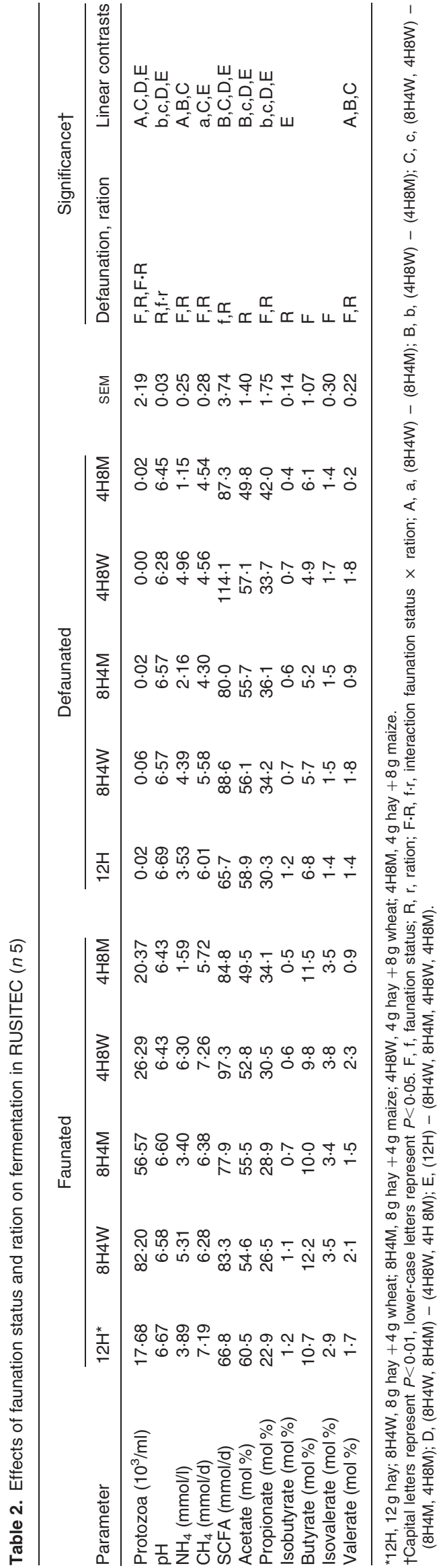


Similarly, the faunated fermenters were associated with slightly more SCFA than the defaunated ones when supplied with the pure hay rations; on average for all the dietary treatments, however, the defaunated fermenters produced more SCFA than the faunated ones. SCFA production was also stimulated when hay was partially replaced by cereal grain, wheat exerting a stronger effect than maize, with the higher replacement rate being more effective than the lower one. The molar proportion of acetate was not influenced by defaunation. It constituted nearly $60 \%$ of SCFA when hay was the only substrate, and it declined with increasing dietary cereal grain proportion, reaching the lowest value of approximately $50 \%$ with the high-maize diet. The molar proportions of propionate were increased by defaunation and by increasing replacement of hay by cereal grain. Maize led to higher propionate proportions than wheat. Isobutyrate remained unaffected by faunation status but was reduced when the mixed hay/cereal grain diets were supplied instead of the pure hay diets. The molar proportions of butyrate, isovalerate and valerate decreased in defaunated fermenters. Maize caused lower molar valerate proportions than wheat.

The effects of faunation status and ration on biotin balances are shown in Table 3. The incorporation of cereal grains instead of hay led to a reduced biotin supply to the fermenters. The faunation status did not significantly affect biotin output in the solid residues, although with hay alone, defaunated had numerically higher values than faunated fermenters. The hay/cereal grain mixtures resulted in a lower biotin concentration in the solid residues than in the treatments with hay alone. In addition, there was a weak tendency for more biotin in solid residues with fermenters receiving the hay/ maize diets than those supplied with the hay/wheat mixtures $(P<0.09)$. Approximately two-thirds (hay ration $12 \mathrm{H}$ ) or up to four-fifths of the total biotin output (all other dietary treatments) were found in the effluent. With the exception of the high-wheat treatments, the defaunated fermenters yielded larger amounts of biotin in the effluent, thus resulting in higher total biotin outputs (solid residue plus effluent) than with the faunated treatments. The biotin balance, calculated as the difference between the total biotin output and the biotin input with the feed, was higher for the defaunated than the faunated fermenters. It was lowest for the pure hay ration. In addition, the fermenters receiving the low cereal grain proportions showed a lower biotin balance than the ones receiving the high proportion. On the high cereal grain level, supplying fermenters with maize led to a slightly positive biotin balance, with a tendency to differ from those receiving wheat $(P<0 \cdot 08)$.

\section{Discussion}

The present investigation was undertaken in continuation of a preliminary RUSITEC study from our laboratory in which increasing proportions of barley grain instead of hay led to significantly elevated protozoal counts as well as a stimulated SCFA production, whereas the net output of biotin by microbial metabolism was reduced (Abel et al. 2001). We speculated that, apart from the rumen bacteria, the protozoa might have contributed to a higher utilisation or a lower synthesis of biotin under stimulated fermentation conditions. In the present study, the fermentation intensity in terms of

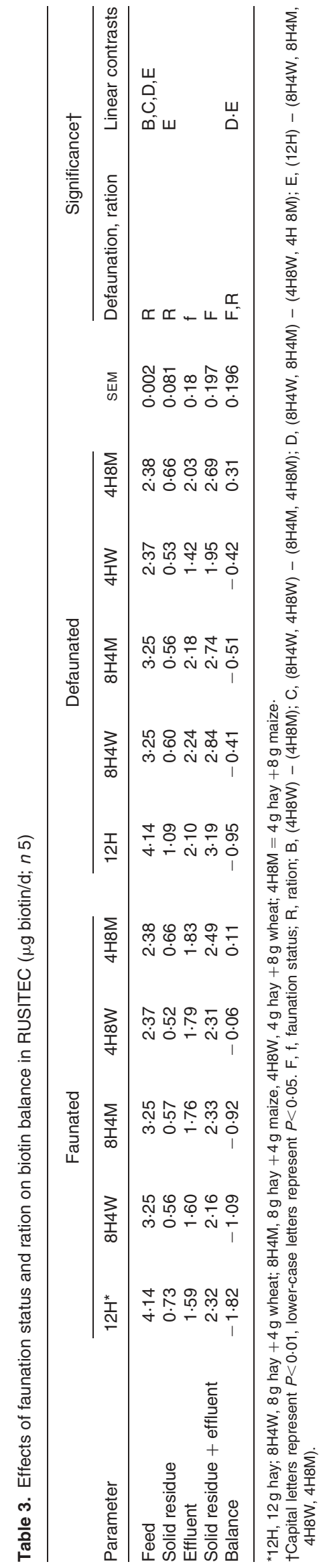


SCFA production was stimulated with increasing replacement of hay by cereal grain. The protozoal counts were elevated with the first level of hay replacement but were again lower in association with the high cereal grain diets. A pH between 6.5 and 7.0 is recommended for optimal protozoal cultivation in vitro (Williams \& Coleman, 1992). In the high-grain supplied fermenters, the average $\mathrm{pH}$ had fallen only slightly below that recommended range. Lower values may, however, have been present in the fermenters during the first few hours after the daily supply of the high cereal grain diets, thus creating an unfavourable milieu for maximal protozoal growth.

The biotin balance in the RUSITEC system depends on the relationship between the amounts supplied with the daily feed rations and the outputs contained in the solid residues and effluents. In agreement with other observations (Aitken \& Hankin, 1970; Scheiner \& DeRitter, 1975), dietary biotin decreased when hay was replaced by cereal grain. Correspondingly, the amount of solid residue biotin was higher in fermenters supplied with hay than with the mixed hay/cereal grain rations. Apart from a non-significant difference in favour of defaunated pure hay supplied fermenters, neither defaunation nor the type and proportion of cereal grains affected the amount of biotin in the solid residues, suggesting that this fraction predominantly represented residual unutilised dietary biotin. A lower utilisation of dietary biotin by rumen microbes has been shown in vitro at a low value of $\mathrm{pH} 5 \cdot 3$ as the result of a lower growth of cellulolytic microbes (Rosendo et al. $2003 a, b$ ). Even though the $\mathrm{pH}$ should not have reached the suggested low value in RUSITEC, it can be assumed that the activity of cellulolytic microbes was reduced with the replacement of hay by cereal grains. It is not possible, however, to clarify the extent to which solid-residue biotin was influenced by the microbial utilisation of dietary biotin.

The positive biotin balances observed in both the faunated and defaunated fermenters supplied with the high-maize diets confirm a microbial synthesis of the vitamin in the RUSITEC system. Mean total biotin output was greater in the defaunated than in the faunated fermenters, indicating a higher synthesis and/or lower utilisation of biotin under these conditions. It is generally assumed that protozoa have only a limited capability and potential for B vitamin synthesis, and biotin utilisation by protozoa has not been demonstrated up until now (Williams \& Coleman, 1992). In the faunated fermenters, there was no correlation between the protozoal counts and biotin output or biotin balance, suggesting that the higher biotin output of the defaunated fermenters not only could be accounted for by a missing protozoal biotin utilisation, but must also have resulted from changed bacterial synthesis and/or utilisation. If protozoa utilise biotin without synthesising it, their requirement appears to be higher in those populations growing on hay rather than the ones growing on mixed hay/cereal grain diets, as the difference between the faunated and defaunated fermenters in biotin output decreased with increasing proportion of dietary cereal grain.

The deviant reaction of the defaunated fermenters supplied with the intensively fermented high-wheat diet, which resulted in the lowest total biotin output of all the dietary treatments, may indicate a high biotin utilisation and/or low biotin synthesis by a selectively grown imbalanced bacterial population. A number of pre-eminent species such as Bacteroides succinogenes, Ruminococcus flavefaciens, Ruminococcus albus,
Butyrivibrio fibrisolvens, Streptococcus bovis, Selenomonas ruminantium and Megasphaera elsdenii have been documented as actually requiring biotin, whereas the potential of rumen bacteria for synthesising this vitamin is still widely unexplored, although the cross-feeding of this vitamin between the microbial species may be essential for their growth and survival (Wolin \& Miller, 1988). For faunated fermenters receiving the high-wheat diet, it must be assumed that the protozoa, although reduced in number in the fermenter fluid compared with the fermenters fed with the lower amounts of cereals, still take up part of the starch, thereby preventing the development of a bacterial population that would utilise high or synthesise low amounts of biotin.

It has long been known that ration changes can produce fluctuations in the ruminal B vitamin balances (Hayes et al. 1966). It can thus be expected that the shift from a fibrerich to a fibre-poor and starch-rich substrate, as in our study, should also have affected the biotin-dependent transcarboxylation reactions. Several prominent rumen micro-organisms, mainly those of potential cellulolytic activity, produce succinate, which is then transformed to propionate (Wolin \& Miller, 1988). Only a few species, predominantly Selenomonas ruminantium, are involved in the decarboxylic transformation of succinate to propionate (Scheifinger \& Wolin, 1973). In our study, the fermenters supplied with the hay diet showed the highest biotin disappearance, leading to the most negative biotin balance. The microbial population developed under the fibre-rich substrate regime may therefore have utilised much of the biotin for propionate production via the succinate pathway. Propionate production was increased when cereal grain partially replaced hay, presumably associated with a shift from the biotin-dependent succinate pathway to the biotinindependent acrylate pathway (Bergner \& Hoffmann, 1996). If so, the microbial population developed under the hay/ cereal grain substrate regimes should have utilised less biotin than when the system was supplied with hay alone.

Unexpectedly, and contrary to our earlier observation (Abel et al. 2001), the biotin balance did not decrease but increased with increasing cereal grain proportion in the diet. However, our earlier and the current study differed in the absolute level of daily feed biotin input $(2.49-1.53 \mu \mathrm{g} v$. 4.14$2 \cdot 37 \mu \mathrm{g}$ ), and the composition of the protozoal population was presumably different between the two investigations as a result of their different periods of adaptation $(6 \mathrm{~d} v .10 \mathrm{~d})$ and adjacent collection periods ( $3 \mathrm{~d} v .5 \mathrm{~d})$. It is well known that, owing to their relatively long generation time and their association with the liquid phase of ruminal contents (Martin et al. 1999), holotrich protozoa cannot survive in RUSITEC. Under such conditions, the protozoal population is rather selectively reduced and changed to one of entodiniomorphs during the first days of adaptation in rumen simulation (Makkar et al. 1995). Even though the different types of protozoa were not determined, it can be assumed that more oligotrich protozoa had survived in our earlier study, whereas in the present study the population was dominated by entodiniomorphs. In addition, the type of cereal (barley in comparison to wheat and maize), as well as differences in the hay quality, may have contributed to the different results in the two studies.

Although the small intestine has been suggested to be the major site of microbial biotin synthesis (Miller et al. 1986), 
and absorption of the vitamin has been confirmed for this intestinal location (Santschi et al. 2005), biotin-dependent metabolic pathways are also important in the overall fermentation process in the rumen. Defaunation increased total biotin output in RUSITEC, suggesting that, under normal faunated conditions, protozoa directly utilise or indirectly affect the synthesis and/or utilisation of biotin by the mixed rumen bacterial population. Defaunation in combination with an extremely intensified fermentation caused low biotin outputs as the result of a reduced synthesis and/or an increased utilisation of the vitamin by the bacteria. Late-cut hay as the sole substrate supplied high amounts of biotin and led to a high disappearance of dietary biotin, indicating a high utilisation by the microbial population. When wheat or maize replaced the hay stepwise, less dietary biotin was provided, but the total biotin output remained on a level similar to that of the fermenters receiving hay as the sole substrate, thus resulting in a less negative, or even a slightly positive, biotin balance. The utilisation of biotin by rumen microbes may be related to propionate production, suggesting that the biotin-dependent succinate or random pathway prevails with a fibre-rich substrate, whereas the biotin-independent acrylate pathway dominates with a substrate rich in starchy cereal grains.

\section{Acknowledgements}

The study was funded by a DFG grant (Ab30/6-1). The authors wish to thank Christine Wurz and Frédérique Wachter, F. Hoffmann-LaRoche AG Basel for their analytical instruction and help in establishing the method of biotin analysis, Rolf Jeromin and Bernardo Lenz for their support in the laboratory, Mom Seng for her assistance in statistics, and Teresa Gatesman for checking the English content of the manuscript.

\section{References}

Abel HJ, Immig I, Da Costa Gomez C \& Steinberg W (2001) Effect of increasing dietary concentrate levels on microbial biotin metabolism in the artificial rumen simulation system (RUSITEC). Arch Anim Nutr 55, 371-376.

Aitken FC \& Hankin RG (1970) Vitamins in Feeds for Livestock. Aberdeen: Commonwealth Agricultural Bureaux/Central Press.

Bergner H \& Hoffmann L (1996) Bioenergetik und Stoffproduktion landwirtschaftlicher Nutztiere. Amsterdam: Harwood Academic Publishers.

Czerkawski JW \& Breckenridge G (1977) Design and development of a long-term rumen simulation technique (Rusitec). Br J Nutr 38, $371-384$.

Frigg M \& Brubacher G (1976) Biotin deficiency in chicks fed a wheat based diet. Int $J$ Vit Nutr Res 46, 314-321.
Frigg M, Straub OC \& Hartmann D (1993) The bioavailability of supplemental biotin in cattle. Int J Vitam Nutr Res 63, 122-128.

Hayes BW, Mitchell GE Jr., Little CO \& Bradley NW (1966) Concentrations of B-vitamins in ruminal fluid of steers fed different levels and physical forms of hay and grain. J Anim Sci 25, 539-542.

McDougall EI (1948) Studies on ruminant saliva. 1. The composition and output of sheep's saliva. Biochem J 43, 99-109.

Makkar HPS, Becker K, Abel HJ \& Szegletti C (1995) Degradation of condensed tannins by rumen microbes exposed to quebracho tannins (QT) in rumen simulation technique (RUSITEC) and effects of QT on fermentative processes in the RUSITEC. J Sci Food Agric 69, 495-500.

Martin C, Devillard E \& Michalet-Doreau B (1999) Influence of sampling site on concentrations and carbohydrate-degrading enzyme activities of protozoa and bacteria in the rumen. J Anim Sci 77, 979-987.

Miller BL, Meiske JC \& Goodrich RD (1986) Effects of grain source and concentrate level on B-vitamin production and absorption in steers. J Anim Sci 62, 473-483.

Milligan LP, Asplund JM \& Robblee AR (1967) In vitro studies on the role of biotin in the metabolism of rumen microorganisms. Can J Animal Sci 47, 57-64.

Naumann K \& Bassler R (1997) Methodenbuch. Die chemische Untersuchung von Futtermitteln. Band III. Darmstadt, Germany: VDLUFA-Verlag.

Poe SE, Mitchell GE Jr. \& Ely DG (1972) Rumen development in lambs. III. Microbial B-vitamin synthesis. J Anim Sci 34, $826-829$.

Rosendo O, Bates DB, McDowell LR, Staples CR, McMahon R \& Wilkinson NS (2003a) Availability and ability of biotin for promoting forage fiber in vitro ruminal digestibility. J Anim Vet Adv 2, 350-357.

Rosendo O, Bates D, Staples CR, McDowell LR, McMahon RJ, Seymour WM \& Wilkinson N (2003b) Is ruminal biotin availability decreased by low pH?" J Anim Sci 81, Suppl. 1, 266.

Santschi DE, Berthiaume R, Matte JJ, Mustafa AF \& Girard CL (2005) Fate of supplementary B-vitamins in the gastrointestinal tract of dairy cows. J Dairy Sci 88, 2043-2054.

Scheifinger CC \& Wolin MJ (1973) Propionate formation from cellulose and soluble sugars by combined cultures of Bacteroides succinogenes and Selenomonas ruminantium. Appl Microbiol 26, 789-795.

Scheiner J \& De Ritter E (1975) Biotin content of feedstuffs. J Agric Food Chem 23, 1157-1162.

Williams AG \& Coleman GS (1992) The Rumen Protozoa, Brock/ Springer Series in Contemporary Bioscience. New York: Springer-Verlag.

Wolin MJ \& Miller TL (1988) Microbe-microbe interactions. In The Rumen Microbial Ecosystem, pp. 343-359 [PN Hobson, editor]. London: Elsevier Applied Science.

Zinn RA, Owens FN, Stuart RL, Dunbar JR \& Norman BB (1987) B-vitamin supplementation of diets for feedlot calves. J Anim Sci 65, 267-277. 